\title{
Nano-Indentation Creep Behavior of the Vacuum Electron Beam Weldment of 12Cr10Co3W2MoNiVNbNB Heat Resistant Steel
}

\author{
Jiankun Xiong ${ }^{1,2,3}$, Jianping Yang ${ }^{2,3}$, Haiyan Zhao ${ }^{1, *}$, Guijun $\mathrm{Mao}^{2,3}, \mathrm{Fen} \mathrm{He}^{3}$, Lin Yang ${ }^{2,3}$ and \\ Yanyan Huang ${ }^{4}$ \\ ${ }^{1}$ School of Mechanical Engineering, Tsinghua University, Beijing 100084, China \\ ${ }^{2}$ State Key Laboratory of Long-life High Temperature Materials, Dongfang Turbine Co., Ltd., Deyang 618000, China \\ ${ }^{3}$ Manufacturing Technology Department, Dongfang Turbine Co., Ltd., Deyang 618000, P.R. China \\ ${ }^{4}$ School of Mechanical Engineering, Chengdu University, Chengdu 610106, China
}

Creep behavior of the weldment of a new type of martensitic heat-resistant steel $12 \mathrm{Cr} 10 \mathrm{Co} 3 \mathrm{~W} 2 \mathrm{MoNiVNbNB}$ joined with vacuum electron beam welding is studied employing nano-indentation technique at room temperature. Different load-displacement curves are obtained for base metal, heat affected zone (HAZ) and weld metal of the welded joint. The creep displacement exhibits a sharp rise at first, then the creep rate continuously decreases with time, and is approaching zero at late steady-state creep. The creep rate of the weld is smaller than HAZ, than base metal for late creep stage. Overall, the indention stress decreases with increasing dwelling time for all the regions, and weld metal yields the greatest indention stress while the base metal has the lowest value. Weld metal exhibits the smallest creep strain rate sensitivity value, indicating it has the best room temperature creep resistance, probably due to the newly formed wide lath martensite. The weldment yields various microstructure for base metal, HAZ and weld metal, and wider martensite laths with a high dislocation density are found in the weld seam. [doi:10.2320/matertrans.MT-M2020345]

(Received November 9, 2020; Accepted February 16, 2021; Published April 25, 2021)

Keywords: martensitic heat-resistant steel, vacuum electron beam welding, nano-indentation creep, hardness

\section{Introduction}

Martensitic heat-resistant steels with 9-12 Cr (mass\%), due to their excellent high-temperature strength, creep resistance and oxidation resistance, have been widely used for the ultra-supercritical (USC) power plants. ${ }^{1)}$ $12 \mathrm{Cr} 10 \mathrm{Co} 3 \mathrm{~W} 2 \mathrm{MoNiVNbNB}$ (Co3W2 for short) is a newly developed martensitic heat-resistant steel, to manufacture mechanical components like bolts and dynamic blades of USC steam turbines. Co3W2 is designed mainly based on T92/91 and P92/91 heat-resistant steels, and its elemental contents are further optimized, for example, new element Co (approximately 3.0 mass $\%$ ) is added and $\mathrm{W}$ content is further increased at the cost of Mo. The study on the weld ability is necessary in the development and application of engineering materials. A great deal of researches have been carried out focusing on weld issues, especially the creep behavior, of the heat-resistant steels employing different welding methods. ${ }^{2-8)}$ Vacuum electron beam welding (EBW), which yields small HAZ region, small welding deformation, weld joints of high strength and fast welding speed, has been adopted to weld such steels. ${ }^{89}$ ) As for Co3W2 discussed in this study, which is designed to manufacture large welded components in USC steam turbines, there were few reports on its welding performance. Recently, the microstructure and mechanical properties like tensile strength of the Co3W2 weld joints with vacuum EBW are investigated in Ref. 9). But, creep behavior of the Co3W2 weldment using vacuum EBW still lacks of detailed research.

Obviously, it is significant for Co3W2 welded components to yield excellent creep strength and creep rupture strength. Room temperature creep behavior of steels is not obvious, so it's difficult to get an accurate creep strain rate sensitivity

*Corresponding author, E-mail: Xjk13@mails.tsinghua.edu.cn using classical uniaxial tensile or compression test. Besides, classical creep tests are not suitable to study individual zones of weldments. Nano-indentation testing can measure the creep properties on the scale of nanometer of different microzones, ${ }^{10)}$ and it has been employed to study room temperature creep of different regions (or microstructures) of steels. ${ }^{11-13)}$ For instance, Ghassemi-Armaki et al. ${ }^{11)}$ conducted nanoindentation to characterize the deformation response of ferrite and martensite in a commercially produced dual-phase sheet steel $(0.15 \mathrm{C} 1.45 \mathrm{Mn} 0.30 \mathrm{Si}$ mass $\%)$. Das et al. ${ }^{12)}$ discussed the deformation behavior of $9 \mathrm{Cr}-1 \mathrm{Mo}$ steel martensitic weldments at room temperature. Therefore, in this paper, room temperature creep behavior of individual zones of Co3W2 weldment produced by vacuum electron beam welding is discussed employing nano-indentation technique.

\section{Experimental and Analysis Methods}

\subsection{Experimental procedure}

The material employed in this study is forged Co3W2 heat resistant steel plate. The chemical composition of $\mathrm{Co} 3 \mathrm{~W} 2$ is $0.13 \mathrm{C}, 0.077 \mathrm{Si}, 0.090 \mathrm{Mn}, 0.013 \mathrm{P}, 0.004 \mathrm{~S}, 10.14 \mathrm{Cr}, 0.79 \mathrm{Mo}$, $0.19 \mathrm{~V}, 0.32 \mathrm{Ni}, 1.79 \mathrm{~W}, 0.006 \mathrm{~B}, 0.086 \mathrm{Nb}, 0.029 \mathrm{~N}, 3.21 \mathrm{Co}$, bal. $\mathrm{Fe}$, mass $\%$. After quenching and tempering treatment, the steel plates for welding with dimensions of $400 \mathrm{~mm} \times$ $150 \mathrm{~mm} \times 50 \mathrm{~mm}$, and of an I-type groove, were prepared. Then, the demagnetization was carried out, to achieve a remanence lower than $2 \mathrm{Gs}$. The two plates were welded by butt weld form utilizing a vacuum electron beam welding machine with a welding speed of $3.3 \mathrm{~mm} / \mathrm{s}$, an accelerating voltage of $125 \mathrm{kV}$, and a beam current of $120 \mathrm{~mA}$; the distance between the steel plate and the electron beam gun was $550 \mathrm{~mm}$. The above parameters can obtain a weld penetration depth of approximately $55 \mathrm{~mm}$. After welding, the welded steel plates were subjected to a heat-treatment at 
$730^{\circ} \mathrm{C}$ for 8 hours for stress relieving. The samples of weld joints were cut from the welded plates, and necessary mechanical polishing or chemical etching were conducted to meet the requirements of the subsequent tests.

Optical metallography and scanning electron microscopy (SEM) equipped with energy dispersive spectroscopy (EDS) were employed to observe the cross sectional microstructure of the samples and obtain the chemical compositions of the region of interest. Micro-hardness measurements conducted in welding zone, heat affected zone and base metal were performed using a HXD-1000-TMC micro-hardness tester. An nano-indentation test at a room temperature of $27^{\circ} \mathrm{C}$, including three stages, loading, dwelling and unloading, is shown in Fig. 1. It took $30 \mathrm{~s}$ to reach the maximum load of $100 \mathrm{mN}$, and the load remains unchanged for $180 \mathrm{~s}$ to analyze the indentation creep behavior. A thermal drift acquisition period, $10 \%$ of the maximum load and $60 \mathrm{~s}$, was contained in the unloading stage, to avoid thermal drift effects. At least 6 effective indents are implemented in the cross section of weld seam, heat affected zone and base metal, respectively, as indicated in Fig. 2, and all experimental data were averaged for improving the precision of the test. The interval between any two adjacent indents was set as no less than $20 \mu \mathrm{m}$, which is sufficient to eliminate the interactions among indents.

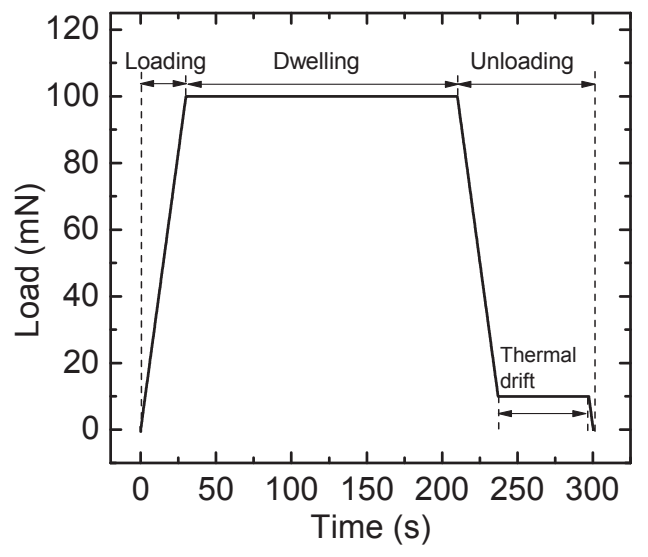

Fig. 1 Nano-indentation process.

\subsection{Calculation principles}

The indentation strain rate $(\dot{\varepsilon})$ in the stage of creeping deformation can be calculated by the following equation: ${ }^{14)}$

$$
\dot{\varepsilon}=\frac{\dot{h}}{h}
$$

where $h$ is the instantaneous indenter displacement, $\dot{h}=\frac{\partial h}{\partial t}$ is the displacement rate.

The hardness of material, $\mathrm{H}$, can be defined as indentation equivalent stress $\sigma:^{14)}$

$$
H=\sigma=\frac{P}{A}=\frac{P}{c h^{2}}
$$

where $P$ is the indentation load, $A$ is the projection of the contact area under an instantaneous load, $c$ is a constant, 24.56, for an ideal Berkovich indenter.

It's easy to obtain the hardness characteristics during indentation test, and the creep process is associated with the expanding speed of the plastic zone towards the interior material. Thus, the relationship between the indentation strain rate and the hardness during the steady-state creep stage can be described as follows: ${ }^{15)}$

$$
H=k \dot{\varepsilon}^{m}
$$

where, $k$ is the material-dependent constant, $m$ is the creep strain rate sensitivity. In the double logarithm coordinate, the relation between the hardness and the indentation strain rate is linear, and the slope is the creep strain rate sensitivity (m), see the following equation:

$$
m=\frac{\partial(\lg H)}{\partial(\lg \dot{\varepsilon})}
$$

\section{Results and Discussions}

\subsection{Microstructure and micro-hardness}

The Co3W2 steel can be joined with vacuum electron beam welding, and the macro-morphology of the welded joint is presented in Fig. 2. The joint includes weld seam, fusion-line, heat-affected zone (HAZ) and base metal. As observed in Fig. 3, the weld, HAZ and base metal yield

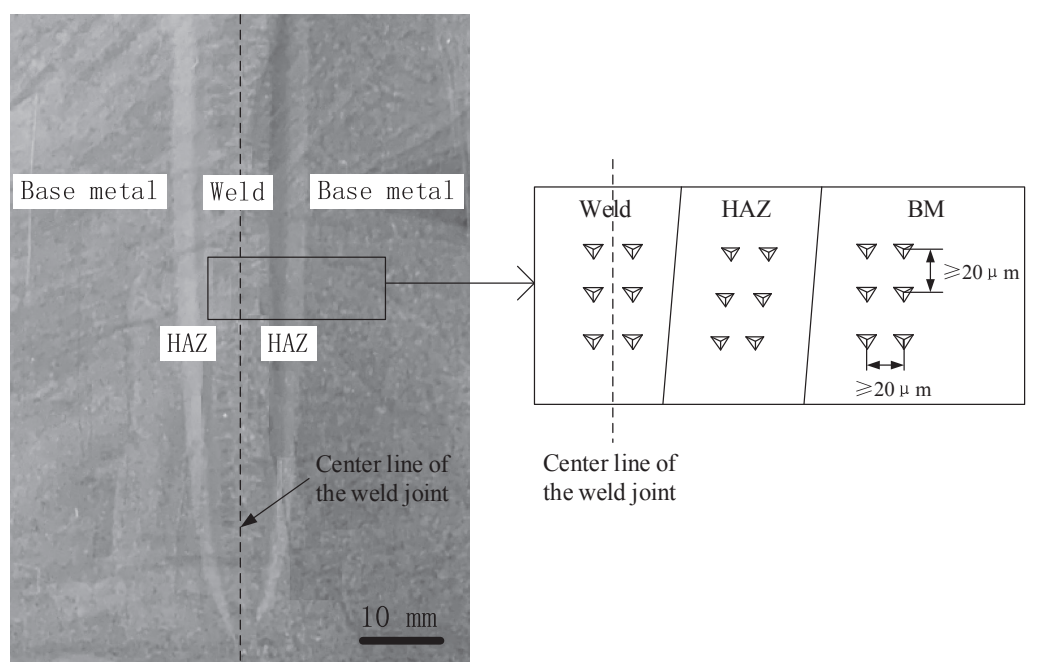

Fig. 2 Macro-morphology and a schematic of nano-indentation points of the $12 \mathrm{Cr} 10 \mathrm{Co} 3 \mathrm{~W} 2 \mathrm{MoNiV}$ NbNB weldment. 

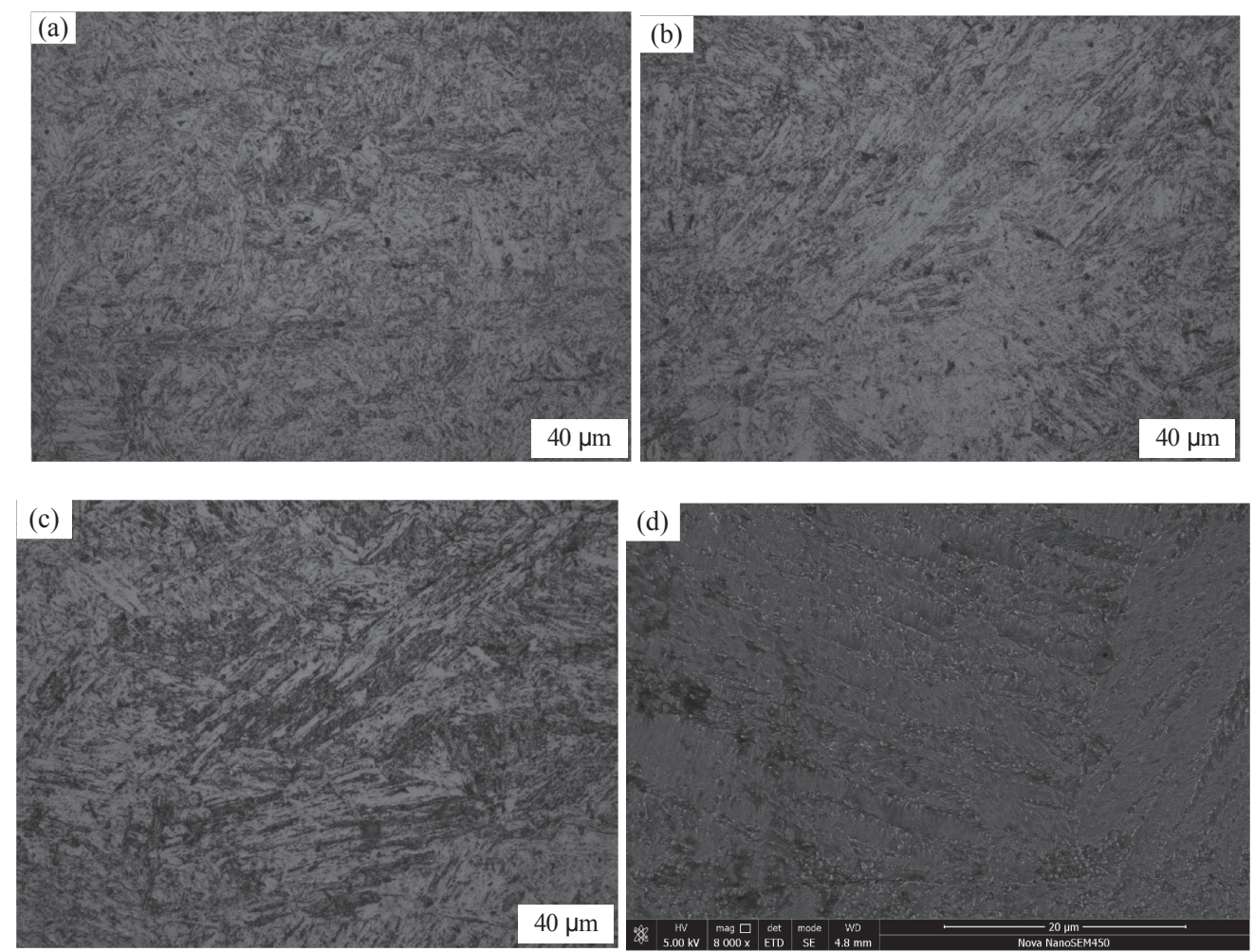

Fig. 3 Microstructure of (a) base metal, (b) heat affected zone and (c), (d) welding zone of the 12Cr 10Co3W2MoNiVNbNB weldment.

different microstructure, after the welding and post-weld heat treatment. The base metal which is remote from the welding zone shows a typical fine-tempered lath martensite, Fig. 3(a). Grains grow and then crystallize in HAZ (Fig. 3(b)), as a result of the localized heating from weld zone and subsequent rapid cooling. Wider martensite laths with a high dislocation density are formed in the weld seam, see Fig. 3(c)-(d). It has been reported that $\mathrm{Nb}(\mathrm{CN}), \mathrm{MX}$, and $\mathrm{M}_{23} \mathrm{C}_{26}$ precipitates can be found in the T92 steel after normalizing and tempering at $750^{\circ} \mathrm{C} .{ }^{16,17)}$ Shigeto Yamasaki et al. ${ }^{18)}$ also observed $\mathrm{M}_{23} \mathrm{C}_{6}$ and MX particles in martensitic packet grains in the grade $\mathrm{P} 92$ ferritic heat-resistant steel, unaged, and aged at $700^{\circ} \mathrm{C}$ for 1000,5000 , or $10000 \mathrm{~h}$. Combining the EDS results, coarsened rod-like $\mathrm{M}_{23} \mathrm{C}_{6}$ type of carbides, which were enriched with $\mathrm{Cr}, \mathrm{Fe}$ and $\mathrm{C}$, could be identified on the lath or grain boundaries in the base, HAZ and weld seam of the weldment. The above observations are in line with previous studies on the weldments of the similar alloys. ${ }^{2,3,9)}$

Micro-hardness values of the weld joint are measured in the vicinity of the weld area, in the direction perpendicular to the vertical center line of the weld joint indicated in Fig. 2, in the upper, middle and bottom region of the welded joint, with an interval of $120 \mu \mathrm{m}$, and are shown in Fig. 4. The location of the vertical center line in the weld seam is at zero on the abscissa axis. In summary, the micro-hardness is symmetrically distributed with respect to the previously defined vertical center line. The hardness in the base metal is around $300 \mathrm{HV}$, and it goes up from the base metal across the HAZ towards the weld zone, and remains stable in the weld area. It is proposed by Zhang et al. ${ }^{9)}$ that the increase of the contents of the main alloying elements $\mathrm{C}, \mathrm{Ni}$ and $\mathrm{Cr}$ and the formation of a $\mathrm{C}$-enriched zone lead to the highest hardness of the weld metal. The hardness results agree with the data measured on

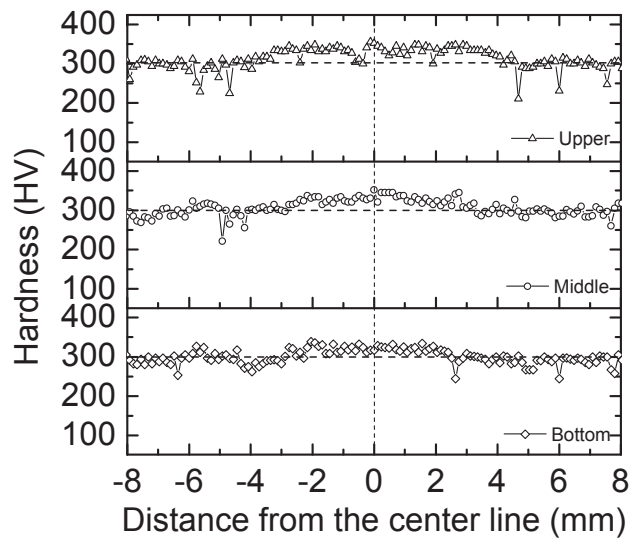

Fig. 4 Micro-hardness of the $12 \mathrm{Cr} 10 \mathrm{Co} 3 \mathrm{~W} 2 \mathrm{MoNiVNb}$ NB weldment.

the weldment of the same alloy also produced by vacuum electron beam welding. ${ }^{9}$ However, it can be further found out in our research that the plateau hardness value shows a downward trend along the vertical line from the upper to the bottom region in the weld seam, and the average hardness values are 339,330 and $320 \mathrm{HV}$, respectively. Furthermore, the plateau's size also decreases towards the bottom of the welded plates, which agrees with the contraction of the weld area as observed in Fig. 2.

\subsection{Nano-indentation results}

Figure 5 displays three typical load-displacement curves as measured in the weld seam, HAZ and base metal zone respectively, employing the nano-indentation technique. It can be seen that three stages, loading, dwelling and unloading, are included for all three curves. When the load goes up to its maximum value $(100 \mathrm{mN})$, the displacement in 


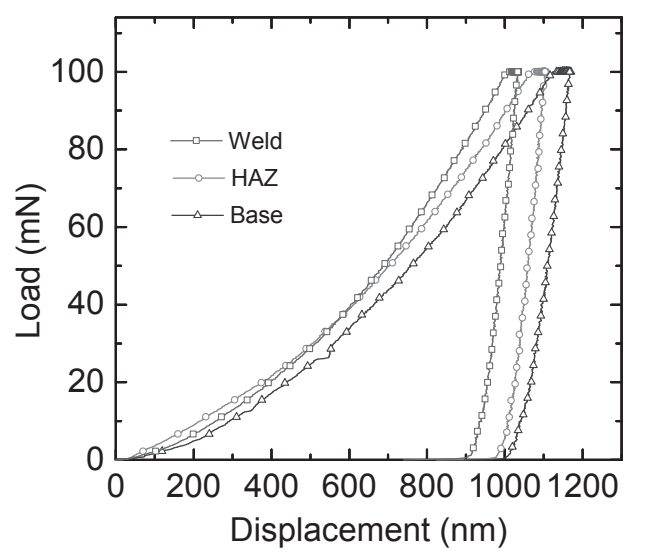

Fig. 5 Typical load-displacement curves of the weld seam, HAZ and base metal of the $12 \mathrm{Cr} 10 \mathrm{Co} 3 \mathrm{~W} 2 \mathrm{MoNi} \mathrm{VNbNB}$ weldment.

the weld metal is the smallest $1005 \mathrm{~nm}$, while the indentation depth in the base metal is the greatest, which is $1124 \mathrm{~nm}$; and, the displacement for the HAZ falls in between, $1067 \mathrm{~nm}$. During the dwelling stage, $100 \mathrm{mN}$ and $180 \mathrm{~s}$ (see Fig. 1), a plateau in each curve can be observed as a result of room creep deformation. The creep displacement values in this stage turn out to be quite different, and they are 28, 38 and $41 \mathrm{~nm}$, for the weld, HAZ and base metal, respectively. The above various relationships between load and displacement in different zones of welded joint are probably due to the microstructure. The newly formed coarse martensite improves material's resistance to localized plastic deformation, which causes a relatively small indentation displacement value in the weld compared to the base metal.

\subsection{Room temperature creep analysis}

A schematic representation of the constant load creep behavior in different areas of the welded joint during dwelling stage with a maximum load of $100 \mathrm{mN}$ and a dwelling time of $180 \mathrm{~s}$, is shown in Fig. 6. Typical creep curve of strain versus time at constant stress and constant elevated temperature in uniaxial tension consists of three regions, and they are in order as follows: transient creep, steady-state creep, and acceleration creep, while generally the metallic materials mainly experiences transient creep and steady-state creep stage in compression creep test. ${ }^{19)}$ As shown in the figure, the creep displacement exhibits a sharp rise at first, then the creep rate continuously decreases with time. This suggests that the material is experiencing an improvement in creep resistance (or strain hardening), i.e., deformation becomes more difficult as the material is strained. For secondary creep, the displacement keeps growing relatively slowly and continuously, and the rate tends to be stable which is associated with the competing processes of strain hardening and recovery. Though the overall changing trend of creep displacement in different zones of the welded joint is similar, the creep rate is still different, which is discussed in the following chapter.

To further discuss the indentation strain rates, the experimental data in Fig. 6 were fitted to an empirical law in Ref. 20), and the fitting constants (A, B, C, D and E) along with the coefficient of determination $\left(\mathrm{R}^{2}>0.96\right)$ for each fit are summarized in the table embedded in the corresponding figure. The creep rate with respect to holding time, up to $180 \mathrm{~s}$, under a maximum load of $100 \mathrm{mN}$, were calculated with the data demonstrated in Fig. 7 employing eq. (1), and displayed in Fig. 7(a). As seen, the creep rate of the weld seam, HAZ and base metal drops dramatically at first and gradually in the subsequent steady-state creep. The creep rate values are approaching zero with the increase of the time, but, the partial enlarged drawing shows that the creep rate of the base is higher than that of the HAZ, higher than that of the weld, indicating that the creep resistance in the weld is the best. The indention stress values were calculated employing eq. (2) with the data in Fig. 5 and displayed in Fig. 7(b). Overall, the indention stress decreases with the increase of dwelling time for all three curves. Under the same load, the maximum indention depth in the base is greater than the HAZ, greater than the weld, thus, the indention stress values in three zones are in inverse relationship and the weld's indention stress turns out to be the greatest.

The creep strain rate sensitivity, $m$, were calculated from eqs. (1), (2) and (4) with the data shown in Fig. 7, and the results are presented in Fig. 8. Indention stress as a function of creep rate is plotted in the double logarithm coordinate, and three curve segments in the steady-state creep are selected for linear fitting process. The creep strain rate sensitivity is the slop of the plot, and is 0.0139 for the weld metal, 0.0190 for the HAZ, and 0.0222 for the base metal. It is known that a smaller creep strain rate sensitivity implies a better material resistance to creep, so the weld metal has the best creep resistance. Though $\mathrm{M}_{23} \mathrm{C}_{6}$ carbides precipitated on the lath or grain boundaries are observed in Fig. 2, they may
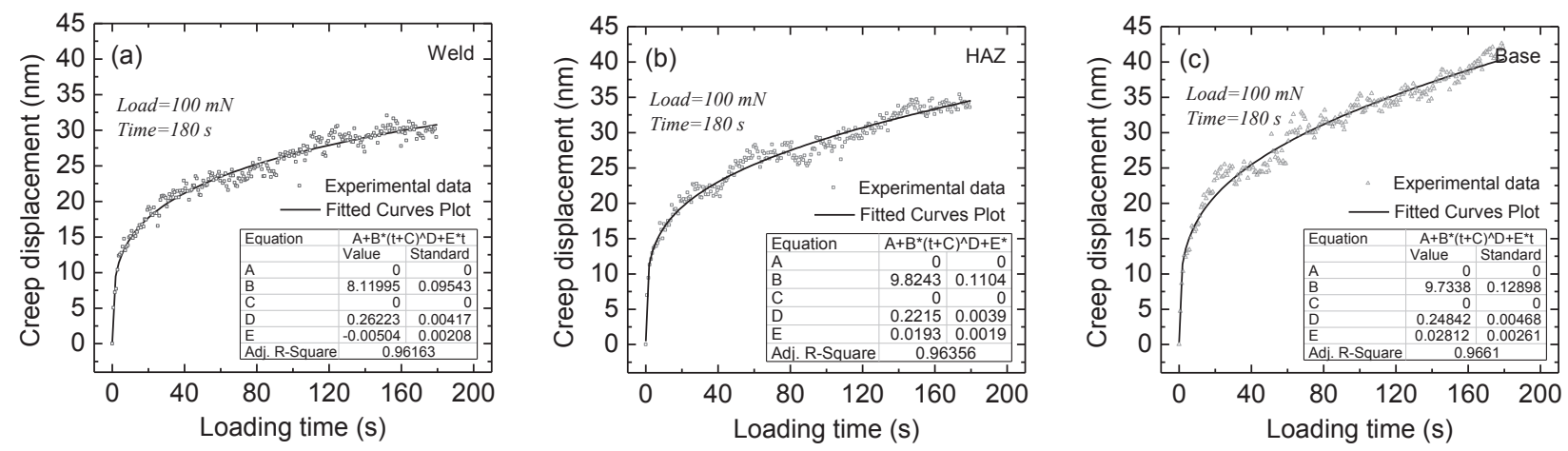

Fig. 6 Experimental and fitted creep displacement-time curves of the (a) weld seam, (b) HAZ and (c) base metal of the $12 \mathrm{Cr} 10 \mathrm{Co} 3 \mathrm{~W} 2 \mathrm{MoNiVNbNB}$ weldment. 

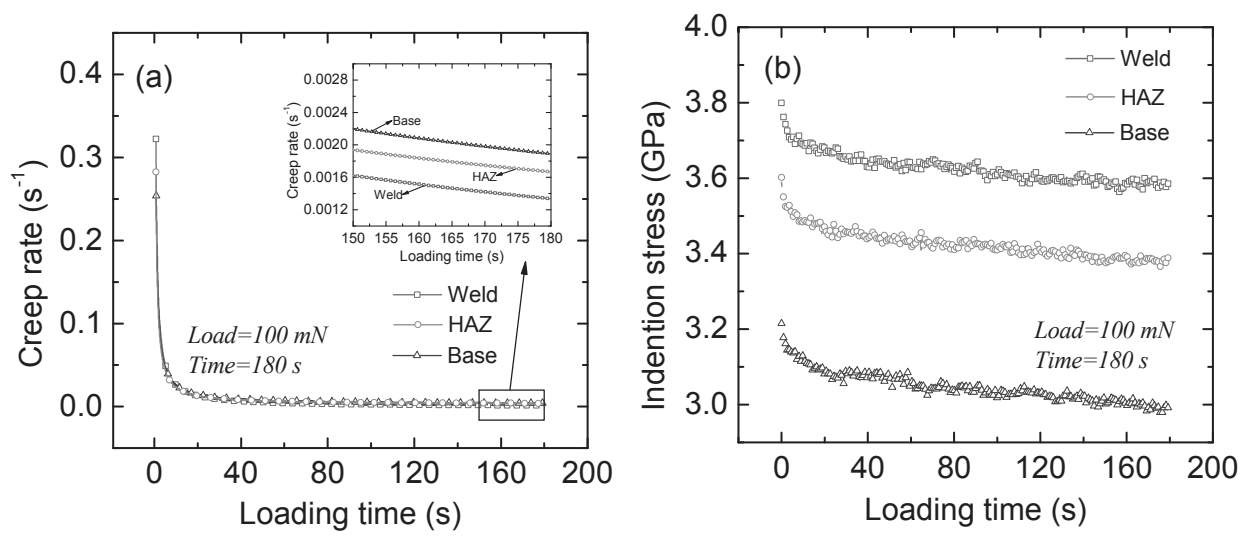

Fig. 7 Relationship between (a) creep rate and time and (b) indention stress and time during dwelling stage, of the weld seam, HAZ and base metal of the $12 \mathrm{Cr} 10 \mathrm{Co} 3 \mathrm{~W} 2 \mathrm{MoNiVNbNB}$ weldment.
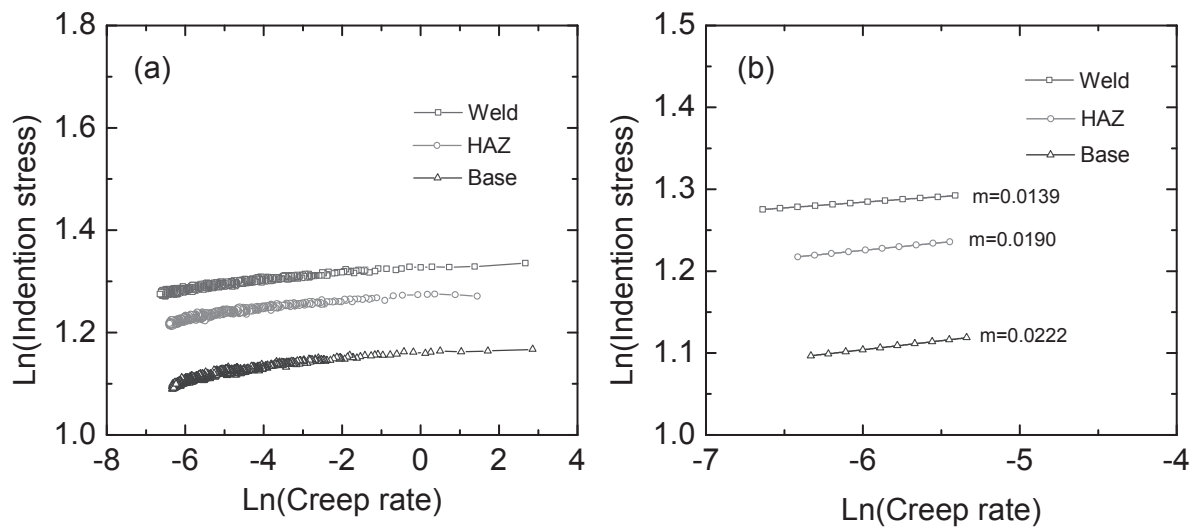

Fig. 8 Double logarithmic plots of indention stress vs. creep rate during (a) dwelling and (b) steady-state creep stage, of the weld seam, $\mathrm{HAZ}$ and base metal of the $12 \mathrm{Cr} 10 \mathrm{Co} 3 \mathrm{~W} 2 \mathrm{MoNiVNbNB}$ weldment.

have little influence on creep strain rate sensitivity when indentation is carried at nano-scale. Researchers have noticed that the creep data measured from nano-indentation creep and conventional uniaxial creep are not in a precise match. For example, Goodall and Clyne ${ }^{21)}$ found that the data measured from nano-indentation creep did not correlate well with those obtained by conventional creep, and a large discrepancy appears between the two creep (or strain) rates and, specifically, the nano-indentation creep rate is faster than the uniaxial creep rate. And, Wang et al. ${ }^{22)}$ conducted two types of creeps on nano-crystalline nickel and observed that the stress exponent $n(n=1 / m)$ was found to be the same, while the strain rate measured by nano-indentation creep was about 100 times faster than uniaxial creep. To fully understand the correlations between nano-indentation creep and uniaxial creep of this specific weldment, it is better to carried out two kinds of creep test, which requires further research.

According previous studies on similar ferritic steel weldments, the creep strength of the base metal is the highest, and the creep rupture tends to appear in the HAZ zone..$^{3,4,6,7)}$ The nano-indention results show that the weld metal shows the best creep resistance, and the HAZ and base metal are more likely to appear creep rapture. Considering that in this study the HAZ zone is not studied with respect to fusion line, inter-critical heat affected zone (ICHAZ), coarse grain heat affected zone (CGHAZ) and fine grain heat affected zone (FGHAZ) in details, the creep rapture location
Table 1 Creep strain rate sensitivity $(m)$ obtained through indentation studies of $12 \mathrm{Cr} 10 \mathrm{Co} 3 \mathrm{~W} 2 \mathrm{MoNiV}$ NbNB weldment in this research, along with P91 and P91B weldment in Ref. 13).

\begin{tabular}{cccccc}
\hline & We1d & Base & \multicolumn{3}{c}{ HAZ } \\
\cline { 4 - 6 } & & & CGHAZ & FGHAZ & ICHAZ \\
\hline Co3W2 weldment & 0.0139 & 0.0222 & & 0.0190 & \\
\cline { 4 - 6 } P91 weldment 13) & 0.033 & 0.021 & 0.03 & 0.0265 & 0.011 \\
P91B weldment & & & & & \\
13) & 0.01872 & 0.01334 & 0.018 & 0.0132 & 0.0117 \\
\hline
\end{tabular}

could be HAZ zone or the base metal, which needs further study. Such discrepancy is likely due to the chemical changes of this new alloy, different post weld heat treatment, different testing temperature, and the choice of welding methods, which reduces the width of the HAZ. Our experimental data of creep strain rate sensitivity, along with $m$ values of P91 and P91B weldment using gas tungsten arc welding (GTAW) process in Ref. 13), are listed in Table 1. Similar to T91, P91 also belongs to $9 \mathrm{Cr}-1 \mathrm{Mo}-\mathrm{V}-\mathrm{Nb}$ steels, and both alloys were produced by adding $\mathrm{V}$ and $\mathrm{Nb}$, and adjusting $\mathrm{Si}, \mathrm{Ni}$ and $\mathrm{Al}$ contents. Herein, the $m$ values of the P91 and P91B (reduced nitrogen concentration and new addition of boron) weldments are comparable with this research. Overall, the data in this research is of the same magnitude as the data in Ref. 13). 
Co3W2 exhibits highest creep strain rate sensitivity in the weld metal, while $m$ value is the greatest in the base metal of the P91 and P91B weldment. The HAZ of P91 and P91B weldment is further divided into inter-critical heat affected zone (ICHAZ), coarse grain heat affected zone (CGHAZ) and fine grain heat affected zone (FGHAZ), while in this study, the middle region of the HAZ is chosen to research. Generally, the $m$ value of HAZ in all the weldments tends to be somewhere in between the values of the weld and base.

\section{Conclusions}

Room temperature nano-indentation creep behavior of a new type of martensitic heat-resistant steel $12 \mathrm{Cr} 10 \mathrm{Co} 3 \mathrm{~W} 2 \mathrm{MoNiVNbNB}$ (Co3W2) produced by vacuum electron beam welding process is investigated employing nano-indentation technique. Weldment yields different microstructure, hardness and creep behavior in weld metal, heat affected zone and base metal. The weld metal is also martensite like the base metal and HAZ, but with wider laths. The micro-hardness rises from the base metal, across the HAZ, and reaches a plateau value in the weld metal, and the plateau's height and width are found to decrease towards the bottom of the weldment. The creep displacement curves with respect to dwelling time in different zones of the welded joint all consist of a transient creep and a steady-state creep stage, yet yielding different creep rate, which drops dramatically at first and gradually in the subsequent steady-state creep stage. The creep rate values are approaching zero with the increasing time, and the value of the weld is smaller than HAZ, than base metal at late steady-state creep stage. Overall, the indention stress in weld metal, HAZ and the base metal all decreases with increasing time, and weld metal yields the greatest value while the base metal has the lowest. The creep strain rate sensitivity is calculated to be 0.0139 for the weld metal, 0.0190 for the HAZ, and 0.0222 for the base metal, which are of the same magnitude as the data in Ref. 13). It's known that a smaller creep strain rate sensitivity implies a better material resistance to creep, therefore the weld metal has the best creep resistance mainly, which is probably as a result of its wider martensite laths with a high dislocation density.

\section{Acknowledgments}

This research was supported by Industry-UniversityResearch Collaboration Project of Deyang, China (grant number 2018CKJ004).

\section{REFERENCES}

1) R. Viswanathan, K. Coleman and U. Rao: Int. J. Press. Vessels Piping 83 (2006) 778-783.

2) Y. Gong, Z.G. Yang and F.Y. Yang: J. Mater. Eng. Perform. 21 (2012) 1313-1319.

3) Y.-Q. Peng, T.-C. Chen, T.-J. Chung, S.-L. Jeng, R.-T. Huang and L.-W. Tsay: Materials 10 (2017) 139.

4) K.S. Chandravathi, K. Laha, P. Parameswaran and M.D. Mathew: Int. J. Press. Vessels Piping 89 (2012) 162-169.

5) S.J. Chen, H.J. Tang and X.T. Jing: Mater. Sci. Eng. A 499 (2009) 114 117.

6) T. Watanabe, M. Yamazaki, H. Hongo, M. Tabuchi and T. Tanabe: Int. J. Press. Vessels Piping 81 (2004) 279-284.

7) J.A. Francis, W. Mazur and H.K.D.H. Bhadeshia: Mater. Sci. Technol. 22 (2006) 1387-1395.

8) F. Abe and M. Tabuchi: Sci. Technol. Weld. Join. 9 (2004) 22-30.

9) Y. Zhang and G. Gou: Int. J. Mod. Phys. B 34 (2019) 501-519.

10) A.C. Fischer-Cripps: Nanoindentation, (Springer, New York, 2004).

11) H. Ghassemi-Armaki, R. Maaß, S.P. Bhat, S. Sriram, J.R. Greer and K.S. Kumar: Acta Mater. 62 (2014) 197-211.

12) H. Ghassemi-Armaki, P. Chen, S. Bhat, S. Sadagopan, S. Kumar and A. Bower: Acta Mater. 61 (2013) 3640.

13) C. Das, S.K. Albert, A.K. Bhaduri and B.S. Murty: Mater. Sci. Eng. A 552 (2012) 419-426.

14) B.N. Lucas and W.C. Oliver: Metall. Mater. Trans. A 30 (1999) 601610 .

15) A.G. Atkins, A. Silverio and D. Tabor: J. Inst. Met. 94 (1966) 369378.

16) S.G. Hong, W.B. Lee and C.G. Park: J. Nucl. Mater. 288 (2001) 202207.

17) S.S. Wang, D.L. Peng, L. Chang and X.D. Hui: Mater. Des. 50 (2013) 174-180.

18) S. Yamasaki, M. Mistuhara, K. Ikeda, S. Hata and H. Nakashima: Mater. Trans. 55 (2014) 842-849.

19) W.D. Callister, Jr.: Fundamentals of Materials Science and Engineering: An Integrated Approach, 2nd Edition, (John Wiley \& Sons, Inc., Hoboken, 2004).

20) J. Xiao, Y. Huang, Q. Zhou, J. Wang and X. He: Surf. Eng. 35 (2019) 719-727.

21) R. Goodall and T.W. Clyne: Acta Mater. 54 (2006) 5489.

22) C.L. Wang, Y.H. Lai, J.C. Huang and T.G. Nieh: Scr. Mater. 62 (2010) $175-178$. 